\title{
Synthesis and Variable Temperature Electrical Conductivity Studies of Highly Ordered TiO2 Nanotubes
}

\section{Citation}

Asmatulu, Ramaazan, Annamalai Karthikeyan, David C. Bell, Shriram Ramanathan, and Michael J. Aziz. 2009. Synthesis and variable temperature electrical conductivity studies of highly ordered TiO2 nanotubes. Journal of Materials Science 44(17): 4613-4616.

\section{Published Version}

doi: 10.1007/s10853-009-3703-5

\section{Permanent link}

http://nrs.harvard.edu/urn-3:HUL.InstRepos:2795734

\section{Terms of Use}

This article was downloaded from Harvard University's DASH repository, and is made available under the terms and conditions applicable to Open Access Policy Articles, as set forth at http:// nrs.harvard.edu/urn-3:HUL.InstRepos:dash.current.terms-of-use\#OAP

\section{Share Your Story}

The Harvard community has made this article openly available.

Please share how this access benefits you. Submit a story.

\section{Accessibility}




\title{
Synthesis and Variable Temperature Electrical Conductivity Studies of Highly Ordered $\mathrm{TiO}_{2}$ Nanotubes
}

\author{
Ramazan Asmatulu ${ }^{\text {a),b) }}$, Annamalai Karthikeyan ${ }^{\text {a) }}$, David C. Bell ${ }^{\text {a), }}$, Shriram Ramanathan ${ }^{\text {a) }}$, and \\ Michael J. Aziz ${ }^{\text {a) }}$ \\ ${ }^{\text {a)} H a r v a r d ~ S c h o o l ~ o f ~ E n g i n e e r i n g ~ a n d ~ A p p l i e d ~ S c i e n c e s ~}$ \\ Cambridge, MA 02138 \\ ${ }^{b)}$ Department of Mechanical Engineering, Wichita State University \\ 1845 Fairmount, Wichita, KS 67260-0133 \\ ${ }^{c}$ Center for Nanoscale Systems, Harvard University \\ Cambridge, MA 02138
}

\begin{abstract}
Rafts of aligned, high aspect ratio $\mathrm{TiO}_{2}$ nanotubes were fabricated by an electrochemical anodization method and their axial electrical conductivities were determined over the temperature range $225-400{ }^{\circ} \mathrm{C}$. Length, outer diameter and wall thickness of the nanotubes were approximately $60-80 \mu \mathrm{m}, 160 \mathrm{~nm}$ and $30 \mathrm{~nm}$, respectively. Transmission electron microscopy studies confirmed that the $\mathrm{TiO}_{2}$ nanotubes were initially amorphous, and became polycrystalline anatase after heat treatment at temperatures as low as $250{ }^{\circ} \mathrm{C}$ in air. The activation energy for conductivity over the temperature range $250-350{ }^{\circ} \mathrm{C}$ was found to be $0.87 \mathrm{eV}$. The conductivity values are comparable to those of nanocrystalline and nanoporous anatase thin films reported in literature.
\end{abstract}

Keywords: Electrochemical anodization of $\mathrm{Ti}, \mathrm{TiO}_{2}$ nanotubes, and electrical conductivity. 


\section{INTRODUCTION}

Titania is of tremendous interest for applications in photovoltaic devices such as solar cells $^{1},{ }^{2}$ photo-catalysis ${ }^{3}$, and photo-electrochemistry ${ }^{5}$. For example, titania is a key component of the dye-sensitized solar cell (DSSC). $\mathrm{TiO}_{2}$ is used to transport electrons from the light absorbing layer (such as $\mathrm{Ru}(\mathrm{dcbpy})_{2}(\mathrm{NCS})_{2}$ dye) to the current collector. Recently, there has been tremendous interest in the use of nanocrystalline titania and mesoporous networks of titania in both DSSCs utilizing liquid electrolytes as well as solid-state solar cells ${ }^{6}, 8 .$, . Mesoporous titania networks are extensively used to investigate performance of solar cells, particularly the Grätzel cell ${ }^{2}$ designs, and several approaches have been developed to fabricate nanostructured $\operatorname{titania}^{6}$. Nanotubes of titania have also attracted attention owing to their potential for application in photovoltaic devices ${ }^{9}$.

In several of these technological applications, understanding the temperature dependent conductivity is critical for understanding device performance, as well as to extract fundamental information on conduction mechanisms and activation energy for carrier transport. ${ }^{10}$ To the best of our knowledge, this paper presents the first electrical conductivity measurements of titania nanotubes.

\section{EXPERIMENTAL}

The fabrication procedure followed closely the method of Grimes and coworkers ${ }^{10,12}$. A $2 \mathrm{~cm} \times 1.5 \mathrm{~cm}$ titanium foil (99.7\%; Sigma-Aldrich) with a thickness of $250 \mu \mathrm{m}$ was immersed into an etching solution containing $0.334 \mathrm{~g}$ of $\mathrm{NH}_{4} \mathrm{~F}$ (Sigma-Aldrich) dissolved into $2.2 \mathrm{ml}$ of DI water and $97.47 \mathrm{ml}$ of ethylene glycol (anhydrous, 99.8\%; Sigma-Aldrich). The solution was mixed for about 15 minutes using a magnetic stirrer bar before the commencement of anodization. The Ti foil was then connected to a working electrode. A Pt counter electrode with the same lateral dimensions and a thickness of $200 \mu \mathrm{m}$ was also immersed into the same solution facing the working electrode. The reference electrode was connected to the potentiostat. The distance between Ti foil and Pt foil was $3.8 \mathrm{~cm}$ and applied voltage ranged from 55 to $75 \mathrm{DC}$ V.

After the anodization was complete, the $\mathrm{TiO}_{2}$ nanotubes, which comprised yellow flakes on both sides of the Ti foil, were washed with isopropyl alcohol and then immersed in a diluted $\mathrm{HCl}(0.1 \mathrm{M})$ solution for $1 \mathrm{hr}$. to remove any unwanted deposits and surface impurities 
introduced during the anodization. Finally, the $\mathrm{TiO}_{2}$ nanotubes were washed again with DI water and dried in an oven at $100{ }^{\circ} \mathrm{C}$ for a few hours.

Measurements of electrical conductivity through the film (i.e. along the axial direction of the nanotubes) were performed on pieces of flakes measuring about $1 \mathrm{~mm} \times 1 \mathrm{~mm}$. Devices were fabricated using silver electrodes on both sides and a stainless steel support plate. Electrodes were attached using pure silver enamel followed by a heat treatment at $70{ }^{\circ} \mathrm{C}$. The stainless steel plate bearing the device was then mounted on a custom designed microprobe electrochemical system. Electrical conductivity measurements were performed in the frequency range of 300 $\mathrm{KHz}-0.1 \mathrm{~Hz}$ using a sinusoidal voltage signal. Conductivity was estimated as conductance divided by electrode area, ignoring the hollowness of the tubes.

\section{RESULTS AND DISCUSSION}

In Figure 1 we present field emission scanning electron microscope (FESEM) images of $\mathrm{TiO}_{2}$ nanotubes formed on the $\mathrm{Ti}$ metal surface. $\mathrm{The}^{\mathrm{TiO}_{2}}$ nanotubes are approximately $60 \mu \mathrm{m}$ long with $160 \mathrm{~nm}$ outer diameter and $30 \mathrm{~nm}$ wall thickness. It has been reported that increasing ammonium fluoride concentration, anodization potential and time result in longer nanotubes ${ }^{10,12}$. However, we found that an anodization potential greater than $75 \mathrm{~V}$ caused dissolution of the surface of the Ti foil instead of the growth of titania nanotubes.

The mechanism of $\mathrm{TiO}_{2}$ nanotubes formation in the $\mathrm{NH}_{4} \mathrm{~F}$ solution has been discussed by Mor et $\mathrm{al}^{12}$. Oxide growth occurs due to the interaction of $\mathrm{Ti}$ with $\mathrm{O}^{2-}$ and hydroxyl ions and subsequent migration occurs due to an electric field gradient. Localized dissolution of the oxide due to the $\mathrm{F}^{-}$ions similar to a corrosion process leads to pitting followed by pore growth. The tube formation occurs due to a geometric electric field intensity enhancement inside the pore region leading to vertical tube growth. Mor et al. have summarized the factors leading to tube array formation by considering the competition between electrochemical etching versus chemical dissolution in a recent review. ${ }^{11}$ The tubes self-organize into a hexagonal array during growth. Indeed we observed a hexagonal array of pits left on the surface of the Ti foil after the growth and removal of the flake of $\mathrm{TiO}_{2}$ nanotubes.

Transmission Electron Microscopy (TEM) studies showed that our $\mathrm{TiO}_{2}$ nanotubes were originally amorphous. After they had been heated to $225{ }^{\circ} \mathrm{C}$ in air, held at these conditions for temperature stabilization and electrical conductivity measurements $(\sim 1 \mathrm{hr})$, and cooled to 
ambient temperature, they were observed to be partly crystalline by TEM. Samples heated to 250 ${ }^{\circ} \mathrm{C}$ in air, held at these conditions for temperature stabilization and electrical conductivity measurements, and cooled to ambient temperature appeared to be fully polycrystalline. Heating and cooling rates of the heat treatment were $1{ }^{\circ} \mathrm{C} / \mathrm{min}$. In Figure 2 we present TEM images of an as-prepared nanotube and of a $250{ }^{\circ} \mathrm{C}$ annealed nanotube. The corresponding TEM diffraction patterns indicate amorphous and polycrystalline anatase, respectively. The first eight rings of the crystalline diffraction pattern, in order of increasing diameter, correspond to the 101, 004, 200, $105+211,204,220+116,215$, and 224 reflections of anatase.

The impedance plot recorded at different temperatures is shown as an inset in Figure 3 in the form of a Nyquist plot. The high frequency part of the spectrum shows a semicircular arc as expected for an RC circuit. The lower frequency part is slightly extended. Polycrystalline titania samples usually show distinct or overlapping semicircular arcs corresponding to bulk and grain boundary responses. The as-prepared nanotubes are amorphous and are free from grain boundaries. However, the microstructures clearly show inter-tube boundary regions and such regions may contribute to distortions in low frequency part of the impedance plot. The conductivity is obtained from the intercept of the impedance curve with the x-axis, taking into account the sample dimensions. ${ }^{12}$ The electrical conductivity of the flakes is found to be $\sim 10^{-8}$ $\Omega^{-1} \mathrm{~cm}^{-1}$ at $300{ }^{\circ} \mathrm{C}$. The electrical conductivity in the temperature range of $250-350{ }^{\circ} \mathrm{C}$ follows Arrhenius form with thermal activation energy of $0.87 \mathrm{eV}$. A deviation from the linear curve is observed above $350{ }^{\circ} \mathrm{C}$ and this may arise from the onset of crystallization processes. The electrical conductivity of the titania nanotubes is comparable to other forms of nanostructured titania. The activation energy observed is close to the values reported for nanoporous anatase ${ }^{13}$. At higher temperatures, however, the activation energy and conductivity approach values reported for nanocrystalline anatase ${ }^{14}$.

\section{SUMMARY}

This work presents the fabrication and characterization of highly ordered $\mathrm{TiO}_{2}$ nanotubes using the electrochemical anodization method. The conductivity of the $\mathrm{TiO}_{2}$ nanotubes is between those of nanoporous and nanocrystalline anatase. The activation energy for electrical transport in $\mathrm{TiO}_{2}$ nanotubes over the temperature range $250-350{ }^{\circ} \mathrm{C}$ was found to be $0.87 \mathrm{eV}$. 
These measurements pave the way for more comprehensive measurements of synthesis/structure/property relationships that are necessary for developing the understanding that is essential for optimal utilization of $\mathrm{TiO}_{2}$ in energy applications.

Acknowledgments: The authors gratefully acknowledge Craig Grimes and his group for helpful discussions and helping us to replicate their $\mathrm{TiO}_{2}$ nanotube synthesis methods, Taeseok Kim for technical assistance and Changhyun Ko for indexing the diffraction pattern. The research of M.J.A. was supported in part by the U.S. Department of Energy grant DE-FG0206ER46335. AK and SR acknowledge GCEP for financial support.. This work was performed in part at the Center for Nanoscale Systems at Harvard University member of the National Nanotechnology Infrastructure Network (NNIN), which is supported by the National Science Foundation under NSF award no. ECS-0335765. 


\section{REFERENCES}

1 H. Wittmer, S. Holten, H. Kliem et al., Phys. Stat. Sol. A-Appl. Res. 181 (2), 461 (2000).

2 M Graetzel, B O'Regan, Nature 353, 737 (1991).

3 U. Diebold, Surf. Sci. Rep. 48, 53 (2003).

4 A. I. Cardona, R. Candal, B. Sanchez et al., Energy 29, 845 (2004).

5 K. Shaw, P. Christensen, and A. Hamnett, Electrochimica Acta 41, 719 (1996); H. Kozuka, Y. Takahashi, G. L. Zhao et al., Thin Solid Films 358, 172 (2000).

6 M Zukalova and L Kavan A Zukal, MK Nazeeruddin, P Liska, M Gratzel,, Nano Lett. 5, 1789 (2005).

7 D Cahen J Bisquert, G Hodes, S Ruhle, and A Zaban,, J. Phys. Chem. B. 108, 8106 (2004).

$8 \quad$ Y Kijitori T Miyasaka, J. Electrochem. Soc. 151, A1767 (2004).

9 G.K. Mor, O.K. Varghese, M. Paulose et al., Solar Energy Materials and Solar Cells 90, 2011 (2006).

10 A.J. Frank, N. Kopidakis, and J. van de Lagemat, Coord. Chem. Rev. 248, 1165 (2004).

11 G. K. Mor, O. K. Varghese, M. Paulose et al., Solar Energy Materials and Solar Cells 90, 2011 (2006).

12 R. Gerhardt, J. Phys. Chem. Solids 55, 1491 (1994).

13 T. Dittrich, J. Weidmann, F. Koch et al., Appl. Phys. Lett. 75, 3980 (1999).

14 B. Huber, A. Brodyanski, M. Scheib et al., Thin Solid Films 472, 114 (2005). 


\section{FIGURES}
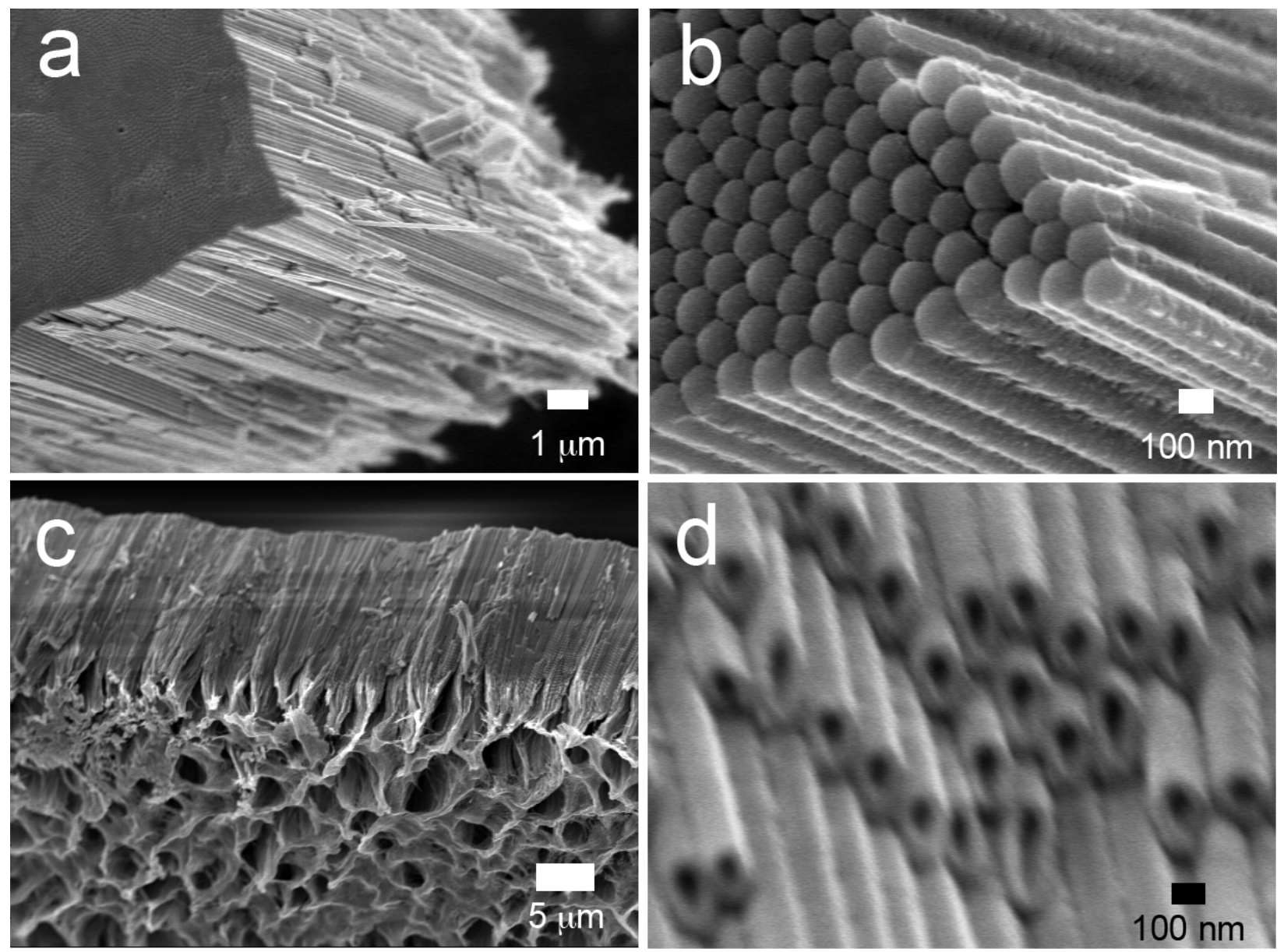

FIG 1: FESEM images of flakes of $\mathrm{TiO}_{2}$ nanotubes formed on the Ti foil after anodization at 55 VDC for 24 hours. (a, b) "back" surface that was in contact with Ti foil before flake peel-off; (c, d) "front" or external surface. The distortion in (d) is due to charging of the sample during imaging. 


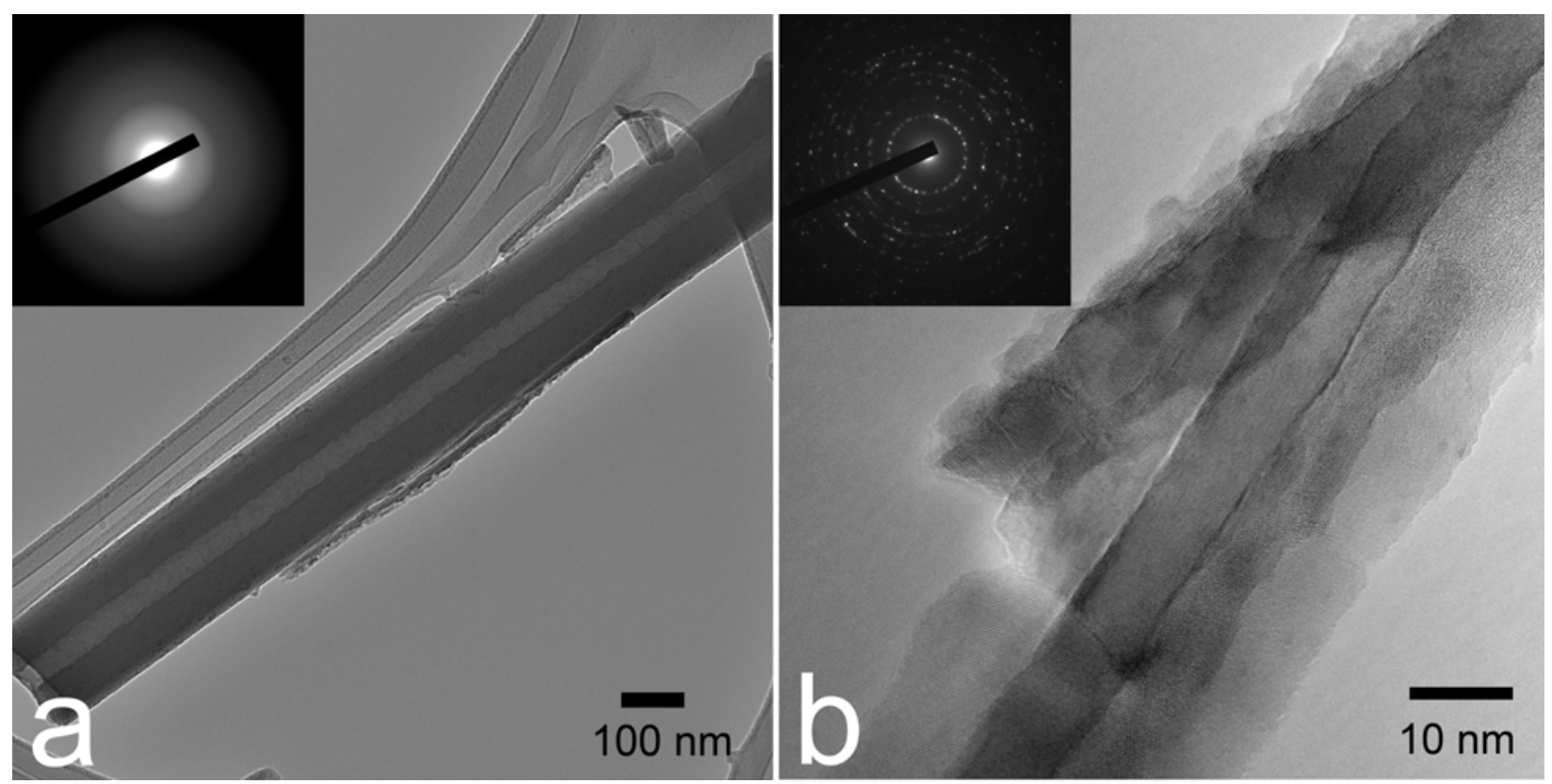

FIG 2: TEM images of $\mathrm{TiO}_{2}$ nanotube samples: (a) as-prepared, and (b) after $250{ }^{\circ} \mathrm{C}$ anneal in air. The insets are the corresponding selected area TEM diffraction patterns. 


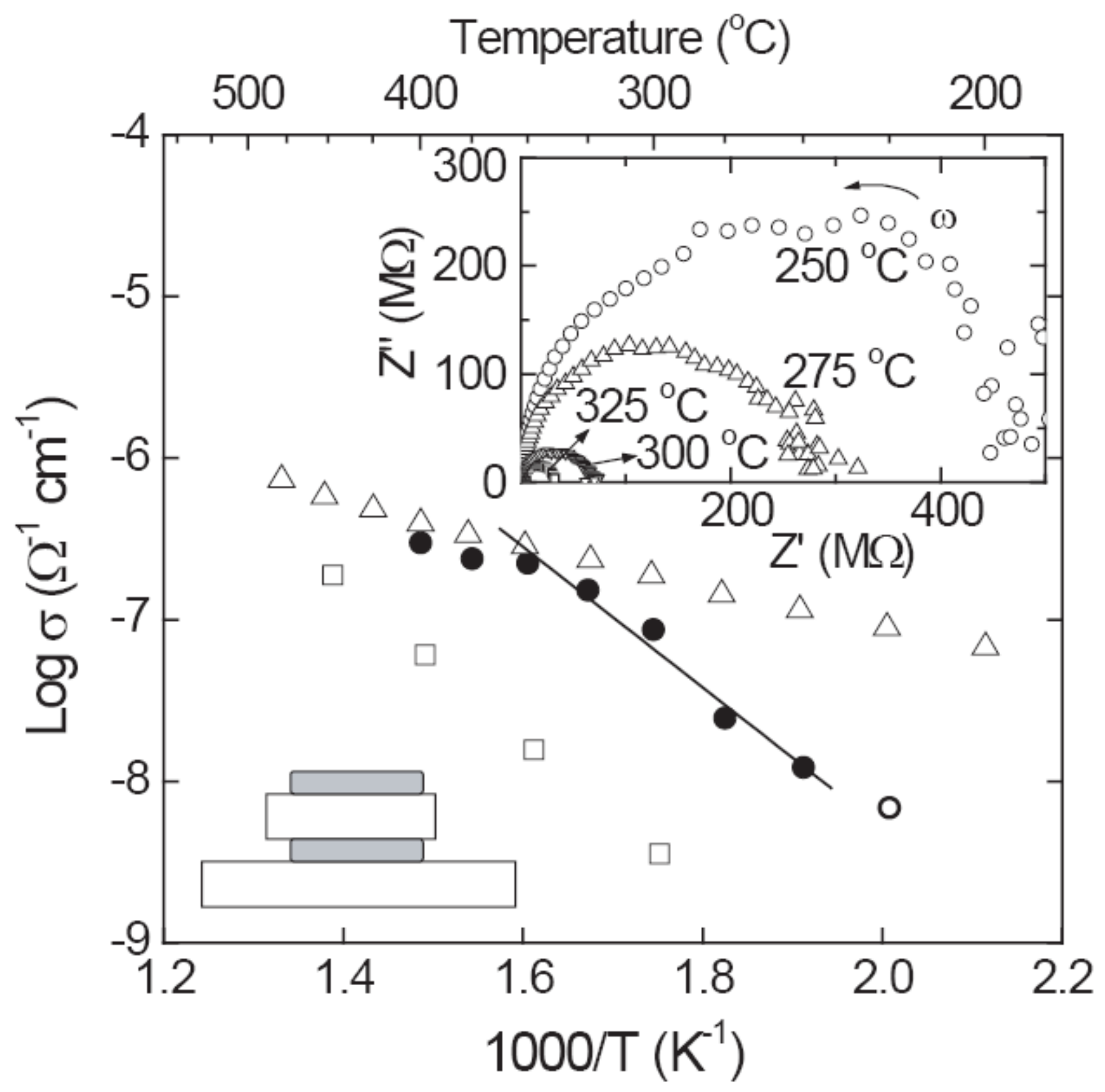

FIG 3: Arrhenius plot of the electrical conductivity of $\mathrm{TiO}_{2}$ nanotubes (circles) in air, with no prior annealing treatment. Sample measured at $225{ }^{\circ} \mathrm{C}$ has a significant amorphous component and is represented by an open circle. The line is fitted to the data from 250 ${ }^{\circ} \mathrm{C}$ through $350{ }^{\circ} \mathrm{C}$. The insets show schematic of measurement geometry and impedance plots at several temperatures. Literature data for nanoporous anatase ${ }^{13}$ (squares) and nanocrystalline anatase $^{14}$ (triangles) thin films are shown for comparison. 